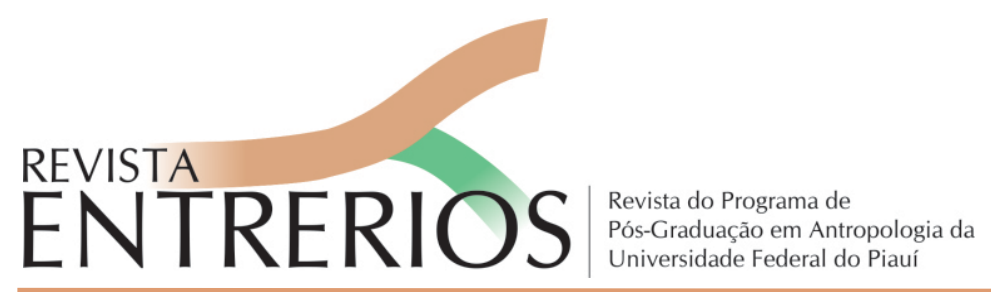

\title{
Concepciones docentes sobre la interculturalidad en la Nueva Escuela Mexicana
}

\author{
Celestina Tiburcio Esteban \\ Estudiante de Doctorado en Investigación Educativa \\ en la Universidad Veracruzana \\ celestinatec@gmail.com \\ Violeta Denis Jiménez Lobatos \\ Doctora en Investigación Educativa \\ por la Universidad Veracruzana \\ violetadj1@gmail.com
}

\begin{abstract}
Resumen: Las políticas educativas poseen rasgos según sea el gobierno que las promueva. Tal es el caso en México de la implementación de la Nueva Escuela Mexicana (NEM) que, fundamentada en humanismo social, busca impactar en los espacios educativos y renovar las prácticas. Pero, después de una década de reformas donde imperaron enfoques sobre educación bicultural, intercultural e inclusiva, los profesores vuelven a ser receptores de discursos que deben apropiar y retomar en sus prácticas didácticas. Por ello, esta investigación analiza las concepciones sobre interculturalidad de seis profesoras de nivel básico (preescolar, primaria y secundaria), a través de una metodología cualitativa y retomando algunos rasgos de la autoetnografía. Se concluye que conceptualizar y trabajar didácticamente la diversidad, desde el enfoque intercultural, aún requiere trascender de perspectivas relacional o funcional (Walsh, 2011) para llegar a una visión crítica que dialogue con los principios de la NEM.
\end{abstract}

Palabras clave: Interculturalidad; educación básica; Nueva Escuela Mexicana; Políticas educativas.

Resumo: As políticas educacionais apresentam características que dependem do governo que as promove. É o caso, do México, na implementação da Nova Escola Mexicana (NEM) que, baseada no humanismo social, busca impactar os espaços educacionais e renovar práticas. Porém, depois de uma década de reformas em que prevaleceram abordagens de uma educação bicultural, intercultural e inclusiva, os professores são novamente receptores de discursos que devem se apropriar e retomar em suas práticas educativas de ensino. Por esse motivo, esta pesquisa analisa as concepções de seis professores sobre interculturalidade; professores estes que pertencem aos níveis (pré-escola, ensino fundamental e médio), e utiliza-se de uma metodologia qualitativa, abordando algumas características da autoetnografia. Os resultados mostram que conceitualizar e trabalhar didaticamente sobre diversidade, a partir de uma abordagem intercultural, ainda requer transcender uma perspectiva relacional ou funcional (Walsh, 2011) para chegar a uma visão crítica que dialogue com os princípios da NEM.

Palavras-chaves: Interculturalidade; Educação básica; Nova Escola Mexicana; políticas educacionais. 


\section{Introducción}

La interculturalidad es un concepto que se incluyó en las reformas educativas mexicanas, con mayor insistencia a partir del año 2006, y desde entonces se ha reflexionado en torno a él a partir de diferentes puntos de vista en el ámbito educativo. El presente estudio resalta el papel que está jugando la interculturalidad en la actual política educativa, cuáles son las perspectivas docentes respecto a este concepto y cómo lo comprenden dentro de sus prácticas en el aula.

El estudio se desarrolla abordando, en un primer momento, un acercamiento histórico a las políticas educativas en México y al enfoque intercultural; enseguida se contextualiza la política educativa mexicana respecto al enfoque intercultural; posteriormente se exponen las orientaciones y los alcances que el enfoque intercultural ha tenido en la educación básica mexicana; luego se hace una síntesis de lo que hasta el momento se ha planteado en la reforma educativa de la educación básica bajo el nombre de Nueva Escuela Mexicana. De igual manera, se dan a conocer las características metodológicas que guiaron a esta investigación, para continuar con la exposición del análisis de los datos y, por último, plantear algunas reflexiones finales.

\section{Acercamiento histórico a las políticas educativas en México y al enfoque intercultural}

En este apartado se describen algunas características que han determinado el rumbo de la educación básica, en términos del tratamiento a la diversidad. Se muestra cómo México trasciende de un enfoque bicultural a un enfoque, nominalmente intercultural, pasando por otro denominado inclusivo y hasta llegar a lo que actualmente denomina Nueva Escuela Mexicana. Se reconocen varios retos o vicios difíciles de superar. Ante la propuesta actual del gobierno mexicano de apostar por una política educativa que reintroduce la intención de "integrar" a la población a través de la denominada "Nueva escuela Mexicana" es necesario conocer y analizar qué se espera lograr en términos del tratamiento de la interculturalidad y qué situación conlleva proponer una "nueva escuela" denominada "Mexicana". Dado que dicha tarea es compleja y amplia, en este estudio analizaremos la perspectiva de diferentes docentes de nivel básico primaria y secundaria sobre lo que para ellos representa la tarea de trabajar didácticamente, desde y para la interculturalidad.

\section{Contexto general de la política educativa mexicana}

Los estudios con el interés de promover una integración de los grupos étnicos a partir del ámbito educativo se remontan a principios del siglo XX con Manuel Gamio, Moisés Sáenz, Julio de la Fuente, Gonzalo Aguirre Beltrán, Herskovitz y muchos otros (BERTELY, 2000, p.17-21). Sin embargo, hacia la década de los 70’s del siglo XX, la educación indígena en Latinoamérica intentó marcar la diferencia entre las culturas bajo un modelo y un currículum estructurado; en él manejaban conceptos como "Bilingüe Bicultural” reconociendo la existencia y enseñanza de las lenguas indígenas como un método pedagógico para transmitir los contenidos de los programas.

Los gobiernos mexicanos entre 1988 y 2010 determinaron la conformación de una legislación pertinente a los cambios que la sociedad ha presentado, hablando específicamente del cambio al sistema económico neoliberal (1988-1994) y que sumerge a México dentro de la ola de la globalización, se destacan las diferencias y respeto entre las culturas. Pero, específicamente, en 1992 se promovió la reforma a la Constitución Política de los Estados Unidos Mexicanos para incluir, en su artículo $4^{\circ}$, la definición del país como multicultural y plurilingüe. 
Años después, en 1997, la educación primaria destinada a poblaciones indígenas cambia su denominación de educación bilingüe bicultural, a educación intercultural bilingüe, otorgando un carácter primordial a la lengua materna, considerándolo como un medio principal para generar aprendizajes en estudiantes indígenas y fortalecer su identidad pues aparte de medio de instrucción se convierte en objeto de estudio.

Entre 1994 a 2000, el gobierno intenta estabilizar las reformas haciendo un reconocimiento trascendental que promueve la unidad nacional entre los grupos étnicos mestizos e indígenas. Así también, en el año 2001, se crea la Coordinación General de Educación Intercultural Bilingüe (CGEIB) que por primera vez plantea el proyecto de generar la educación intercultural para toda la población y la educación culturalmente pertinente para los indígenas a todos los niveles educativos. La misión de esta coordinación es contribuir en la construcción de una sociedad más justa y equitativa, mejorando y ampliando las oportunidades educativas de la población indígena y promoviendo relaciones más igualitarias y respetuosas entre los miembros de distintas culturas.

Durante el periodo 2000 a 2006 se puso en marcha la política de fortalecimiento de la atención educativa a la población indígena con la finalidad de mejorar la educación indígena en México. Su objetivo principal fue atender a los grupos indígenas con calidad y pertinencia cultural, de manera que alcanzaran los objetivos nacionales de la educación básica, logrando un bilingüismo oral y escrito efectivo, conozcan y valoren su propia cultura.

Hacia 2006, el enfoque de la interculturalidad en la educación cambia en la política educativa mexicana, de un sentido integracionista hacia una pretendida transversalización educativa, se plantea entonces una interculturalidad para todos los mexicanos (SCHMELKES, 2004). En la Reforma Integral de la Educación Básica se plantea el término interculturalidad como un rasgo deseable de un egresado de educación básica; el concepto es asumido como riqueza y forma de convivencia en la diversidad social, étnica, cultural y lingüística, así como una propuesta educativa que tiene la finalidad de mejorar la comunicación y la convivencia entre distintas culturas, anteponiendo el respeto mutuo (SEP, 2011).

Con el cambio de sexenio se suscitaron algunas modificaciones en el planteamiento político y educativo de la interculturalidad. El Plan Nacional de Desarrollo 2013-2018 del gobierno de Enrique Peña Nieto consideró la estrategia de México Incluyente que buscaba "transitar hacia una sociedad equitativa e incluyente" por lo que implementó el Programa Especial de los Pueblos Indígenas 2014-2018 que se propuso fomentar el bienestar de los pueblos y comunidades indígenas, fortaleciendo su desarrollo económico y social, en el marco de un respeto pleno al ejercicio de sus derechos y a las manifestaciones de su cultura. En este periodo se observa un énfasis conceptual por el enfoque inclusivo.

Actualmente el Gobierno de México, del presidente Andrés Manuel López Obrador (2018-2024), en lo que llama cuarta transformación Nacional, reconoce a los Pueblos Indígenas y Afromexicano como sujetos de derecho público por lo que ha diseñado un Programa Nacional de Pueblos Indígenas, con perspectiva intercultural, considerando que dichos pueblos tienen la capacidad de definir libremente sus formas de organización política, así como su desarrollo económico, social y cultural, conforme a lo establecido en la legislación nacional e internacional. Asimismo, dicho programa se fundamenta en los principios de libre determinación, integralidad, pertinencia social, económica y cultural, sostenibilidad y territorialidad, transversalidad, igualdad de género y participación y consulta.

La preocupación por la educación intercultural es mundial. Se tiene la necesidad de que los sistemas educativos se preparen para una sociedad multicultural, a fin de lograr una cohesión social basada en el respeto mutuo entre grupos culturales distintos. Así lo han manifestado diversas reuniones de la Organización de las Naciones Unidas (ONU) y los países miembros de la OCDE. Este último organismo solicita que los países desarrollen diversas propuestas formativas que sean capaces de responder eficazmente a los cambios venideros para que la sociedad se adapte a los cambios.

EntreRios - Revista do PPGANT -UFPI -Teresina • Vol. 3, n. 1 (2020) 
En este sentido, el concepto de interculturalidad en el ámbito educativo intenta cumplir con un objetivo integracionista (DIETZ, 2009; PÉREZ RUÍZ, 2009), pero esto es un proceso que sigue su curso. Las instituciones educativas federales y estatales saben que una verdadera interculturalidad debe manifestar una convivencia y comunicación respetuosa entre culturas, así lo expresan en su discurso las políticas educativas emanadas por dichas instituciones, sin embargo, lo que sucede en la realidad dista mucho de lo que se plasma en los documentos oficiales.

\section{Enfoques sobre la Interculturalidad: orientaciones y alcances}

El término "intercultural" es polisémico y en ocasiones se le asocia con características del discurso multicultural. Hablar de él requiere reflexionar sobre la relación y el reconocimiento entre diferentes culturas pero también en considerarlas en un ámbito de convivencia armónica, respetuosa y productiva. Para Mato (2005, p.120) “las culturas” son las "personas y/o grupos sociales que se auto-identifican y/o son identificadas por otros, como 'productoras' y/o 'portadoras' de ciertas 'culturas' que resultan ser diferentes entre sí'. Es así que, en el campo de los estudios interculturales, es necesario advertir la especificidad del contexto societal a partir del que se aborde o estudie las minorías a atender, pues, hay orientaciones desde un marco discursivo del post o neoindigenismo, que toma como eje de análisis al sujeto indígena, $u$ orientaciones basadas en las minorías prototipo de origen migrante, ya sea contemporáneo o ancestral (DIETZ; MATEOS CORTÉS, 2013).

En México, como parte de la política educativa del gobierno de Vicente Fox Quesada 20012006 se creó la Coordinación General de Educación Intercultural y Bilingüe (CGEIB) y fue en ese sexenio que el término bicultural fue sustituido por el de intercultural que concibe "las culturas dentro de un proceso interactivo, complementario e incluyente enmarcado dentro de procesos de intercambios globalizados y se aleja de un enfoque culturalmente excluyente" (JIMÉNEZ, 2011, p.43). A pesar de que el giro de lo bicultural a lo intercultural fue más nominal que real, Jiménez (2011, p.42) señala que ese cambio era producto de un debate anterior que indicaba que lo bicultural "no reflejaba ni el carácter dinámico de la cultura ni la capacidad del ser humano de aumentar su espectro cultural". De cualquier manera, ese giro no logró solventar muchos de los problemas que planteó el enfoque bicultural, como qué de "lo propio" y qué de "lo ajeno" habrá de enseñarse y aprenderse en las escuelas bilingües en contextos indígenas o cómo los conocimientos y los procesos de enseñanza-aprendizaje que tienen lugar al interior de las comunidades tengan presencia en el espacio escolar (JIMÉNEZ, 2011).

La interculturalidad, de acuerdo con Walsh (2011), se aborda desde tres perspectivas: la relacional, funcional y crítica. La perspectiva relacional contempla, en términos generales y básicos el contacto e intercambio entre culturas (personas, prácticas, saberes, valores y tradiciones culturales distintas), a nivel individual, e incluso en condiciones de desigualdad, por tanto, es un enfoque que ha existido desde la colonización porque oculta y minimiza la conflictividad, los contextos de poder, racialización, dominación y colonialidad (WALSH, 2011).

En la perspectiva funcional, la interculturalidad se identifica cuando los Estados reconocen la diversidad con la intención de "resolver el problema de las minorías" integrándolas a la sociedad nacional y a la estructura social de facto (WALSH, 2011). Se promueve el diálogo, la convivencia y la tolerancia, sin el afán de cambiar el sistema existente ni cuestionar las asimetrías o desigualdades sociales o culturales en él. Por ello, la función de la interculturalidad es integrar o incluir a las minorías a un sistema propio de un modelo neoliberal que usa el reconocimiento y respeto a la diversidad como estrategia de dominación social. En este sentido, es un enfoque de la interculturalidad más abierto pero a la vez sigue reproduciendo la concepción de hacer que lo diverso sea visualizad como un problema y por ello darse a la tarea de integrarlo al status quo de la sociedad. 
En la tercera perspectiva la interculturalidad se entiende críticamente, desde un punto de vista social, político y epistémico. No reconoce a la diversidad como problema ni considera su existencia en términos generales, pues lo que problematiza es la estructura colonial-racial. La interculturalidad se considera una herramienta, un proceso y proyecto que nace de la gente para transformar las estructuras, instituciones y las relaciones sociales impuestas por un sistema económico o político. Por ello, se modifican "las condiciones de estar, ser, pensar, conocer, aprender, sentir y vivir distintas; es decir un accionar" (WALSH, 2011, p.102). Bajo esta perspectiva la interculturalidad se percibe más como un verbo de permanente reflexión, relación y negociación en un marco contextual donde prima el respeto, la legitimidad, simetría, equidad e igualdad. Es esta perspectiva crítica la que se retomará en este estudio para analizar los discursos de los docentes en función de lo que ellos entienden por interculturalidad, cómo la practican y promueven en sus aulas.

Por su parte, Dietz (2011) identifica tres dimensiones a través de las cuales se concibe la interculturalidad. La primera dimensión la denomina "inter-cultural" y se enfoca "en las complejas expresiones y concatenaciones de praxis culturales y pedagógicas que responden a lógicas culturales diferentes" (DIETZ, 2011, p.16). Es aquí donde el conflicto cultural se entendería a partir del contexto histórico y cultural de los sujetos, analizando las razones por las que cada grupo realiza ciertas prácticas, comprendiendo las distintas lógicas del ser y hacer.

La segunda dimensión se llama "inter-actoral" la cual "valora y aprovecha las pautas y canales de negociación y mutua transferencia de saberes" (DIETZ,2011, p.16), se refiere más a los actores y la forma en que interactúan, comunicándose, intercambiando, información, saberes y en cómo valoran dichas acciones. La tercera dimensión es la "inter-lingüe" que aprovecha las competencias sustanciales y relacionales "que hacen posible la traducción entre horizontes lingüísticos y culturales tan diversos pues pretende desarrollar las competencias comunicativas y "traductológicas" (DIETZ, 2011, p.17). Aquí se hace hincapié en la importancia de promover relaciones que comprendan el lenguaje, en el marco de un contexto cultural y lingüístico que permita traducir los saberes.

Encontramos puntos de encuentro entre las dimensiones descritas con la perspectiva crítica de la que habla Walsh (2011) por ejemplo, en la necesidad de estar en constante vigilancia para advertir los conflictos culturales provenientes de lógicas distintas, hacerles frente, entenderlas, reflexionarlas para, en la medida de lo posible, hacer un cambio. En ese sentido, el sujeto debe apreciar la diversidad, negociando e intercambiando saberes; poner en práctica y desarrollar sus competencias comunicativas para traducir y negociar no sólo cuestiones lingüísticas, sino también los aspectos culturales.

\section{La Nueva Escuela Mexicana}

La Nueva Escuela Mexicana (NEM) es el nombre que se le da al proceso de implementación de la política educativa nacional por parte del Estado mexicano. Esta política tiene una característica más gubernamental que pública (CABRERO, 2000), pues surge del proyecto de gobierno del presidente actual, Andrés Manuel López Obrador (2018-2024). Tiene como antecedente los foros de consulta a la sociedad civil por un Acuerdo Educativo Nacional, entre los que destacan maestras, maestros, investigadores del campo educativo, madres y padres de familia, estudiantes y organizaciones civiles, llevados a cabo entre los meses de agosto y noviembre de 2018. Dichos foros orientaron algunos ejes de acción de dicha política (SEP, 2019, p.4). La NEM impactó directamente en la Constitución de los Estados Unidos Mexicanos. Los artículos $3^{\circ}, 31^{\circ}$ y $73^{\circ}$ fueron modificados a partir del 15 de mayo de 2019. 


\begin{tabular}{|c|c|c|}
\hline Artículo $3^{\circ}$ (Educación) & $\begin{array}{l}\text { Artículo } 31^{\circ} \\
\text { (Obligaciones de los } \\
\text { mexicanos) }\end{array}$ & $\begin{array}{l}\text { Artículo } 73^{\circ} \quad(\mathrm{E} 1 \\
\text { Congreso) }\end{array}$ \\
\hline $\begin{array}{l}\text { La educación inicial será parte de la } \\
\text { educación básica obligatoria. } \\
\text { La educación ahora se basa en un } \\
\text { enfoque de derechos humanos y de } \\
\text { igualdad sustantiva. } \\
\text { Fomentará el respeto a los derechos, } \\
\text { libertades y cultura de paz. } \\
\text { Promoverá honestidad, valores y la } \\
\text { mejora continua del proceso de enseñanza } \\
\text { aprendizaje. } \\
\quad \text { La educación contribuirá al respeto } \\
\text { por la naturaleza. } \\
\quad \text { Todos tenemos derecho a gozar del } \\
\text { desarrollo de la ciencia e innovación } \\
\text { tecnológica. } \\
\text { El Estado apoyará la investigación e } \\
\text { innovación cientifica y humanistica. } \\
\text { El Estado garantizará el acceso a la } \\
\text { información que se derive de la } \\
\text { investigación, ciencia y tecnología. } \\
\text { Se crea el Sistema Nacional de Mejora } \\
\text { Continua, éste sustituye al INEE. Pone } \\
\text { énfasis en las evaluaciones formativas e } \\
\text { integrales del Sistema Educativo Nacional. } \\
\text { Se crea una Junta directiva en lugar de } \\
\text { una Junta de gobierno. } \\
\text { Tanto la Junta directiva como el } \\
\text { Consejo Técnico de Educación deberá } \\
\text { estar conformado por especialistas en } \\
\text { investigación, política educativa, temas } \\
\text { pedagógicos o tener experiencia docente en } \\
\text { cualquier tipo o modalidad educativa. } \\
\text { Se adiciona que corresponde al Estado } \\
\text { la rectoría de la educación, la impartida por } \\
\text { éste, además de obligatoria, será universal, } \\
\text { inclusiva, pública, gratuita y laica. }\end{array}$ & $\begin{array}{l}\text { Cambia la frase: } \\
\text { "hacer que sus hijos, } \\
\text { o pupilos concurran a } \\
\text { las escuelas", a "ser } \\
\text { responsables". } \\
\text { Se incluye a las } \\
\text { hijas (por cuestiones } \\
\text { de género). } \\
\text { Se aclara hasta } \\
\text { qué edad los padres o } \\
\text { tutores serán } \\
\text { responsables de que } \\
\text { sus hijas, hijos o } \\
\text { pupilos reciban } \\
\text { educación ry } \\
\text { obligatoria: } \\
\text { "menores de } 18 \\
\text { años". } \\
\text { Se agrega que los } \\
\text { padres o tutores } \\
\text { deberán: participar en } \\
\text { el progreso y } \\
\text { desempeño, velar por } \\
\text { su bienestar y } \\
\text { desarrollo de sus } \\
\text { hijos, hijas o pupilos. }\end{array}$ & $\begin{array}{l}\text { Se sustituye el } \\
\text { establecimiento de un } \\
\text { Servicio Profesional } \\
\text { docente por el } \\
\text { Sistema para la } \\
\text { Carrera de las } \\
\text { maestras y los } \\
\text { maestros. } \\
\text { Se agrega el } \\
\text { establecimiento, } \\
\text { organización } \\
\text { sostenimiento de de } \\
\text { escuelas de nivel } \\
\text { medio superior. } \\
\text { Se agrega que el } \\
\text { Congreso tiene la } \\
\text { facultad para legislar } \\
\text { en materia de ciencia, } \\
\text { tecnologia } \\
\text { innovación, } \\
\text { estableciendo bases } \\
\text { generales } \\
\text { coordinación entre } \\
\text { federación, estados y } \\
\text { municipios para } \\
\text { consolidar el Sistema } \\
\text { Nacional de Ciencia, } \\
\text { Tecnologia a } \\
\text { Innovación. }\end{array}$ \\
\hline
\end{tabular}




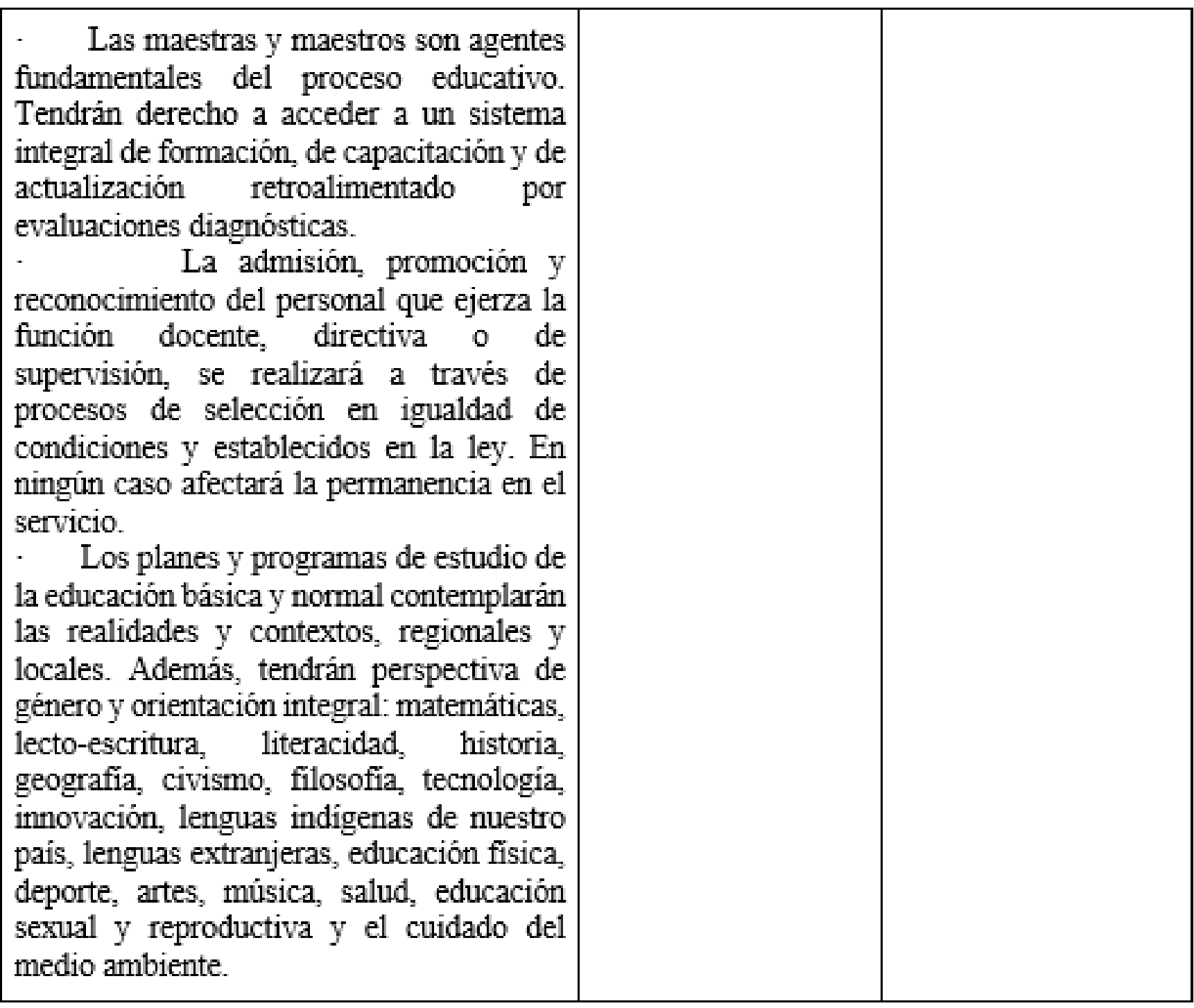

Fuente: Elaboración propia basada en los artículos $3^{\circ}, 31^{\circ}$ y $73^{\circ}$ de la Constitución mexicana.

El Acuerdo Educativo Nacional, diseñado para derogar la Reforma Educativa implementada en 2013, también se ve reflejado en la Ley General de Educación; la Ley reglamentaria para la mejora continua de la educación; y la Ley General del sistema para la carrera de las maestras y los maestros. Todos estos documentos legales destacan el reconocimiento de las maestras y los maestros como agentes de cambio para la transformación social; el establecimiento del interés superior de niñas, niños, adolescentes y jóvenes en el acceso, permanencia y participación en la educación; la obligatoriedad del Estado para impartir educación gratuita y de calidad en todos los niveles educativos; la atención prioritaria a comunidades indígenas y zonas de alta marginación, y la eliminación de cualquier acto que atente contra la dignidad del magisterio.

Como se ha visto, los cambios propuestos por el Acuerdo Educativo Nacional son de orden legislativo, administrativo, laboral y pedagógico, y tienen como objetivo sentar las bases de un nuevo modelo educativo. En el Taller de Capacitación magisterial llevado a cabo en agosto de 2019, se expone que los primeros pasos a seguir hacia la NEM son:

- Ubicar a las Niñas, Niños y Adolescentes al centro del quehacer de la escuela.

- No dejar a nadie atrás y a nadie afuera del máximo logro de aprendizajes. Equidad, inclusión y excelencia en nuestra escuela.

- Vivir la honestidad, generosidad, empatía, colaboración, libertad y confianza en los planteles escolares. Fortalecer la educación cívica en todos los grados. 
- Fortalecer la convivencia familiar, a fin de que las madres y padres participen activa y positivamente en la formación integral de nuestros estudiantes.

- Promover el arte y la actividad física como herramientas potentes para el desarrollo emocional, físico e intelectual de los estudiantes.

- Impulsar la educación plurilingüe e intercultural (SEP, 2019, p.14).

El modelo educativo que promueve la NEM se basa en el humanismo social con la intención de tener un perfil de egreso orientado a la ciudadanía crítica, la empatía, fortalecer los valores de la responsabilidad y el respeto, la participación, así como el compromiso con la comunidad y con los ambientes natural y social. La NEM es un proyecto que se autodefine como horizontal, flexible, plural y abierto. Continúa en construcción hacia una nueva política educativa mexicana y tiene contemplado concretizarse a partir del ciclo escolar 2021-2022.

La NEM retoma diferentes documentos normativos como la constitución política. Por ejemplo, en el artículo $3^{\circ}$ constitucional se caracteriza a los planes y programas de estudio con la interculturalidad, "al promover la convivencia armónica entre personas y comunidades para el respeto y reconocimiento de sus diferencias y derechos, en un marco de inclusión social” (SEP, 2019, p.26). Los rasgos que se identifican de la interculturalidad son: convivencia armónica, respeto, reconocimiento, derechos, inclusión social; se ofrecen adjetivos positivos de las relaciones humanas que nos llevan a pensar en la unidad social, la solidaridad ciudadana y existe un marcado énfasis en la diferencia que implica la libertad del ser, su respeto y la legislación la garantiza a través de los derechos humanos.

Como se observa, en pleno siglo XXI, el Estado promueve esos rasgos de la interculturalidad, pero ¿qué pasa con los conflictos?,¿porque se pone énfasis en el aprender a convivir? ¿cómo se ha orientado y se orientará a los futuros ciudadanos mexicanos a apreciar, traducir y entender las lógicas del conflicto con la diferencia? pues en la práctica, se requiere que las estructuras educativas trabajen en conjunto, se apropien de los enfoques pedagógicos e intenten modificar sus actividades didácticas en función de las orientaciones de las políticas interculturales. Además, aparte del enfoque intercultural, en el mismo artículo 3o se establece que la educación que brinde el estado debe cubrir otros criterios, entre los que se destacan el inclusivo e integral. En cuanto a lo inclusivo, la constitución se refiere al tratamiento, ajustable según las diversas capacidades, circunstancias y necesidades de los educandos para superar las barreras para el aprendizaje y la participación. Asimismo, el criterio integral se liga a la atención de capacidades cognitivas, socioemocionales y físicas, es decir, la atención de todas ellas.

Sin duda, es deseable que a nivel constitucional se planteen requisitos mínimos para que el sistema educativo funcione, sin embargo, la complejidad la amplitud de enfoques es evidente y es probable que tantas orientaciones no sean nítidas para los actores encargados de ponerlos en operación o simplemente, de llevarlos a la práctica. En esta línea sería deseable que se retomarán más políticas públicas en lugar de implementar políticas educativas gubernamentales, considerando que las políticas gubernamentales "son percibidas, definidas, diseñadas, ejecutadas y evaluadas casi exclusivamente desde el gobierno" (CABRERO, 2000, p.195).

\section{Características metodológicas del estudio}

Entender la interculturalidad de la manera en que hasta aquí se ha argumentado implica una serie de consecuencias para promoverla y para abordarla didácticamente. Asimismo, considerando que estamos en un ciclo escolar de muchos cambios, por las orientaciones pedagógicas propias de cada reforma sexenal, este estudio se detiene en el tiempo de agosto 2019 a marzo 2020 y se guía por los siguientes cuestionamientos ¿Qué han reconocido los docentes sobre los cambios en la política educativa mexicana, en materia de interculturalidad?, ¿cómo pe- 
-rciben el concepto de interculturalidad? y principalmente ¿cómo lo llevan a la práctica en el aula?

Para abordar las interrogantes anteriores partimos de un enfoque cualitativo, es decir, interpretativo y naturalista con referencia a su objeto de estudio que aborda la realidad en su contexto natural recuperando los significados que le otorgan las personas implicadas en dichas prácticas que, en este caso, son profesores de nivel básico que laboran en escuelas primarias y secundaria ubicados en contextos rural y urbanos en el estado de Veracruz, México.

Rodríguez, G., Gil J., y García E. (1999) señala que la investigación cualitativa tiene varios significados, implica utilizar y recoger diversos y variados recursos como entrevistas, experiencia personal, historias de vida, observaciones, textos históricos imágenes, entre otros. Además, esta investigación retoma rasgos de la autoetnografía, porque las autoras, al ser docentes frente a grupo formamos parte de la comunidad de estudio, la conocemos y hemos experimentado las características de los procesos de formación. Así se conecta la esfera personal, con lo cultural (ELLIS, 2003; RICHARDSON, 2003) corriendo el riesgo de que sea difícil distinguir ambas "a veces más allá de un reconocimiento propio" (ELLIS, 1999, citado por BLANCO, 2012, p.56). La autoetnografía, como metodología de investigación, ha sido concebida en el tránsito "de lo que son las biografías y las autobiografías ubicadas en el paradigma positivista - con su lucha por "volverse científicas" - al polo opuesto que representa la propuesta autoetnográfica, con una mezcla indisoluble entre las dimensiones tradicionalmente llamadas objetivas y subjetivas" (BLANCO, 2012, p.57)

Con base en lo anterior, analizar las concepciones docentes sobre el enfoque intercultural ante la implementación de la NEM, bajo el enfoque de la investigación cualitativa produjo datos descriptivos a partir de las propias palabras de las personas, habladas o escritas y de su conducta observable (TAYLOR; BOGDAN, 1986). Los docentes contestaron una encuesta autoadministrada y se sistematizaron algunas observaciones que, como docentes, realizamos al formar parte de una plantilla docente que participa periódicamente en Consejos Técnicos Escolares, y en algunos cursos presenciales, es decir, por desempeñarnos laboralmente como profesoras en el contexto de estudio, primaria y secundaria, fue posible realizar observación participante registrando datos cercanos a la realidad que desde fuera (investigadores externos o no docentes), son imposibles de percibir. Por ello el marco metodológico de este estudio lo engloba este enfoque.

La técnica de investigación fue la entrevista autoadministrada que consistió en un cuestionario de cinco preguntas abiertas y un apartado de datos generales. Dicho cuestionario se les envió a los profesores a su correo electrónico quienes lo descargaron, respondieron e hicieron llegar por el mismo medio. Para Leonardo Rocco (2007) la encuesta digital provee nuevas posibilidades como reducir costos, ser más rápida pero la calidad de respuesta, diseño muestral, los conocimientos técnicos y población son variables importantes a evaluar según las particularidades y objetivos de cada estudio o proyecto de investigación. Este tipo de encuestas, para Vidal Díaz de Rada (2011) permite que los entrevistados presenten mayor confianza en comparación de las encuestas con encuestador.

Se tomó registro de observaciones (observación participante) de las últimas dos reuniones de Consejo Técnico que se realizaron y de al menos una capacitación docente que en total sumaron 20 horas de observación.

Las encuestas fueron enviadas a profesores, en total se enviaron ocho cuestionarios y se recuperaron seis cuestionarios de profesoras de entre 4 a 21 años de servicio; cuatro de ellas tienen posgrado en educación, una en psicoterapia Gestalt y otra de ellas tiene doble licenciatura. Cuatro docentes laboran en el ámbito urbano, en la capital del estado de Veracruz y las otras dos profesoras laboran en comunidades rurales. 
Análisis de los datos: entre el discurso y la práctica intercultural

Las prácticas discursivas están ligadas a enunciados y las no discursivas refieren a visibilidades (RESTREPO, 2004). Es decir, las prácticas discursivas son aquellas que se pronuncian, que se dicen, que se hablan y las no discursivas son los actos, el comportamiento, los haceres. A través del estudio de las prácticas discursivas no se pretende estudiar "los significados ocultos de las palabras y los textos sino un cuidadoso escrutinio de los enunciados y visibilidades en sus múltiples conexiones, emergencias, rupturas, dispersiones y desapariciones" (RESTREPO, 2004, p. 78). En este caso, analizamos la información que nos hicieron llegar las profesoras en sus encuestas.

Enseguida se muestran los resultados de las entrevistas respecto a cinco aspectos: 1) ¿Qué se entiende por interculturalidad? 2) ¿Cómo trabaja la interculturalidad en sus clases? 3) ¿En qué espacios se ha formado en temáticas sobre interculturalidad? 4)¿Qué entiende por la Nueva Escuela Mexicana? 5) ¿Cuál es el enfoque para trabajar la diversidad en la Nueva Escuela Mexicana?

\section{Concepciones docentes sobre la interculturalidad}

La primera pregunta de la encuesta fue ¿qué entiende por interculturalidad? cada docente escribió su respuesta y a continuación, retomando las tres perspectivas del enfoque intercultural (WALSH, 2011) se clasifica cada una de ellas, considerando que forman parte de sus prácticas discursivas pero no se limitan a ellas.

Cabe señalar que, es probable que el docente posea una perspectiva sobre lo que es la interculturalidad pero no necesariamente sea reflejo de sus prácticas pues puede omitir, de manera inconsciente, cierta información porque existen diferentes acciones que son prácticas culturales invisibles.

\begin{tabular}{|l|l|l|l|}
\hline \multicolumn{1}{|c|}{ Profesora } & Relacional & Funcional & Crítica \\
\hline $\begin{array}{l}\text { Forma de vida que te permite establecer un proceso de } \\
\text { comunicación e interacción entre personas. } \\
\text { Reconociéndonos como parte de la diversidad. (L6SB) }\end{array}$ & & & \\
\hline $\begin{array}{l}\text { Intercambio de ideas entre grupos de personas de } \\
\text { diferentes nacionalidades. (M4SI) }\end{array}$ & & \\
\hline $\begin{array}{l}\text { Proceso de interacción y comunicación entre varias } \\
\text { personas, donde el objetivo fundamental debe centrarse } \\
\text { en el respeto hacia la diversidad, así como en el } \\
\text { intercambio de ideas (L4SH) }\end{array}$ & & \\
\hline $\begin{array}{l}\text { Interacción que se da entre diferentes culturas } \\
\text { respetando sus costumbres y favoreciendo el diálogo } \\
\text { (M21PRI) }\end{array}$ & & \\
\hline $\begin{array}{l}\text { Proceso donde interactúan personas de distintas } \\
\text { culturas, donde existe respeto mutuo y se trata a todos } \\
\text { por igual. (C18PRE) }\end{array}$ & & \\
\hline $\begin{array}{l}\text { Modelo a seguir. Se puede llegar a ser intercultural a } \\
\text { través del respeto, comprensión, aceptación y tolerancia } \\
\text { hacia el otro. Va más allá de dejar ser al otro, de } \\
\text { entender cómo es y por qué es así, se trata de dialogar } \\
\text { constantemente (L15PRE) }\end{array}$ & & & \\
\hline
\end{tabular}


Estas percepciones se enfocan a la interculturalidad desde el punto de vista de la comunicación y aceptación de la diferencia, sin embargo, aunque la mayoría tiene una visión del diálogo, intercambio y respeto, sólo una docente hizo alusión al principio de igualdad, que es un rasgo en el que hace énfasis la NEM. Además, se encuentran en el tránsito de trascender de una perspectiva funcionalista a una crítica de la interculturalidad.

Analizando las definiciones, a partir de las diferentes dimensiones de la interculturalidad que señala Dietz (2011), se encontró que ninguna definición abordó las tres dimensiones; la mayoría abordó la intercultural e interactoral, mientras que la dimensión inte-lingue fue la menos referida. La mayoría coincidió en que la interculturalidad se relaciona con el tratamiento igualitario, reconocimiento y respeto a la diversidad (dimensión inter-cultural), y pusieron énfasis en que implica interactuar, comunicarse e intercambiar ideas (dimensión inter-actoral). Finalmente, la mayoría concibe la interculturalidad como un proceso y, sólo una maestra, comentó que es una forma de vida.

\section{La interculturalidad en el aula}

La segunda pregunta tenía la intención de acercarnos a la visión didáctica del enfoque intercultural. Como se observará, también tienen diferentes énfasis de acuerdo con las perspectivas relacional, funcional y crítica y en consecuencia, también muestran diferencias en los rasgos de las dimensiones inter-cultural, inter-actoral e inter-lingüe (DIETZ, 2011).

¿Cómo trabaja la interculturalidad en sus clases?

\begin{tabular}{|l|l|l|l|}
\hline \multicolumn{1}{|c|}{ Profesora } & Relacional & Funcional & Crítica \\
\hline $\begin{array}{l}\text { Cuando les doy la oportunidad a mis alumnos de expresarse } \\
\text { y escuchar su opinión (L6SB) }\end{array}$ & & & \\
\hline $\begin{array}{l}\text { Las actividades de mi materia se prestan para trabajar } \\
\text { constantemente la interculturalidad, haciendo cuadros } \\
\text { comparativos, diálogos, sketches, obras de teatro, etc. } \\
\text { (M4SI) }\end{array}$ & & & \\
\hline $\begin{array}{l}\text { A través de la convivencia, el respeto al diálogo, diversidad } \\
\text { y puntos de vista de los alumnos. Asimismo, se procura } \\
\text { trabajar temáticas donde el alumno tenga oportunidad de } \\
\text { reflexionar, analizar, ya que la finalidad es integrarlo de } \\
\text { forma armónica en una actividad (L4SH) }\end{array}$ & & & \\
\hline $\begin{array}{l}\text { Reconociendo a los niños como seres individuales y } \\
\text { diferentes, promoviendo el respeto entre pares y tratando } \\
\text { de conocer los diferentes espacios, características, usos y } \\
\text { costumbres del grupo (M21PRI) }\end{array}$ & & & \\
\hline $\begin{array}{l}\text { Favoreciendo el diálogo entre los alumnos, compartiendo } \\
\text { ideas, y respetando costumbres para que exista una mejor } \\
\text { convivencia entre los ellos (C18PRE) }\end{array}$ & & & \\
\hline $\begin{array}{l}\text { Informar sobre la dinámica cultural de otros grupos } \\
\text { sociales. Trabajo la convivencia, el aprender a convivir. } \\
\text { Intento que practiquen la tolerancia critica, comprensiva y } \\
\text { respeten las diferentes formas de pensar, ser, vivir e incluso } \\
\text { convivir (L15PRE) }\end{array}$ & & & \\
\hline
\end{tabular}


Tomando en cuenta que la perspectiva crítica de la interculturalidad busca transformar las prácticas vigentes para contribuir en la conformación de una sociedad igualitaria, respetuosa en permanente reflexión, relación y negociación, por las respuestas, no fue posible ubicar alguna de ellas en dicha perspectiva dado que no es suficiente la práctica respetuosa, sino que también se requiere de un marco contextual respetuoso, legítimo, simétrico, equitativo e igualitario.

En cuanto a las dimensiones de la interculturalidad (DIETZ, 2011), es evidente el énfasis en la dimensión inter-actoral y la inter-cultural, pues señalan la importancia del diálogo, respeto a costumbres, promoción de convivencia y la comprensión de la dinámica cultural de los distintos grupos.

\section{La formación de la interculturalidad en el docente}

La formación docente, inicial y continua, que promueve la comprensión del enfoque intercultural se traduce en cursos que la secretaría o ministerio de educación ha diseñado a través de los Consejos Técnicos Escolares o cursos exclusivos para atender dicha temática. Sólo una profesora señaló que recibió un par de temáticas del enfoque en su formación inicial.

Por otro lado, se observan diferencias en cuanto al alcance de la formación docente, pues no sólo se remiten al proceso formal e inicial (exclusivo de la licenciatura) de cursar y aprobar un curso sino que hacen referencia a la experiencia docente en el tratamiento del enfoque intercultural, por ejemplo, la maestra L6SB señaló que también se ha formado a través de la experiencia de la "dinámica al trabajar con el grupo o al leer algunos [textos] de la asignatura de biología". Como también se observa, transversalizan la interculturalidad con los contenidos de las materias que imparten pues sus estudios o carrera "se 'presta' para el intercambio culturas de los idiomas y su cultura” (M4SI). Este último rasgo se relaciona directamente con la dimensión inter-lingue a la que Dietz (2011) atribuye la traducción de significados, más allá de los aspectos bilingües.

Al menos dos profesoras señalaron que la formación en el enfoque, en su caso, ha trascendido el ámbito escolar, porque lo han retomado a "su propia experiencia de vida, de la cotidianeidad, los pueblos, así como en las ciudades y espacios pequeños, el propio centro de trabajo, y las personas con quienes nos relacionamos" (L4SH). En este punto, se observa la dimensión inter-actoral del enfoque intercultural que Dietz (2011) señala.

La formación inicial docente en México muestra desfases con las necesidades que se requieren en las escuelas una vez que el docente ingresa al magisterio. Esto es consecuencia de la falta de continuidad en las distintas políticas gubernamentales (CABRERO, 2000) y a la escasa promoción de formación continua en cuestiones de la didáctica intercultural.

\section{Concepciones de los docentes de la Nueva Escuela Mexicana}

La cuarta pregunta se formuló para identificar cómo están percibiendo los docentes el enfoque de los cambios en la política educativa mexicana. Como se señaló, dicha política es más gubernamental que pública (CABRERO, 2000) y aún se encuentra en proceso de implementación y transformación, lo que explica que los profesores la entienden desde diferentes enfoques.

Algunos profesores ponen énfasis en la currícula, que la NEM es "la renovación de la currícula adaptable a los contextos y la formación integral de los adolescentes" (L6SB), es decir, ponen de manifiesto que se trata de una renovación. Sin embargo, la currícula es un elemento que se ha contemplado poner al conocimiento del magisterio en el año 2021, por lo que todavía no se tiene clara cuál va a ser su estructura ni sus contenidos. 
Otro énfasis del profesorado es que la NEM valora el papel del docente, poniéndolo al centro al igual que a los estudiantes, "reconoce al docente como agente de cambio de la transformación social, así mismo se reconoce a los estudiantes como el interés prioritario de la educación que imparte el estado" (M4SI), considerando, por ello, que se trata de un enfoque humanista (C18PRE).

Los profesores tienen muy claro que la NEM tiene como base el humanismo, al tomar como sujetos claves tanto al docente como al estudiante, pero también al considerar el apoyo que deben brindar los padres de familia. Señalan que "el objetivo primordial de ésta [NEM] es el fomento de la armonía social, la solidaridad, el trabajo en equipo y la empatía” (M4SI), por ello, expresan que se ve fortalecido el papel de la formación cívica en la escuela al promover una mejor convivencia familiar (M21PRI).

No obstante, los profesores opinan que los objetivos que se plantea la NEM tiene muchos retos, ya que no es tarea fácil crear una sociedad democrática, donde se atienda la diversidad y la equidad, así como "trabajar más allá de lo cognitivo, como lo moral, y lo cívico encaminado hacia una educación humanista" (L4SH). "Si bien existieron (en otros gobiernos) cambios en lo administrativo, pedagógico y laboral, hasta el momento no se han logrado ver los resultados que ellos refieren" (C18PRE).

Por otra parte, el profesorado reconoce que la NEM pone un mayor interés en la población marginada, "trata de unificar o integrar a todos los grupos que conforman el espacio geográfico de la República Mexicana, pero da énfasis a los que han sido desfavorecidos" (L15PRE).

Para resumir, las concepciones de los docentes acerca de la NEM giran en torno a cuatro ámbitos: el curricular, el enfoque humanista, las adversidades o áreas de oportunidad y la integración de la población. Si bien, no se expresó que se trata de un proceso de implementación de la política educativa del gobierno en curso, se reconocen elementos que, de acuerdo con su experiencia, no se habían considerado en otras reformas educativas.

\section{La diversidad que se reconoce en la Nueva Escuela Mexicana}

Al preguntarles sobre cuál es el enfoque para trabajar la diversidad en la Nueva Escuela Mexicana, las maestras brindaron diferentes respuestas. Cuatro de ellas aludieron al enfoque humanista, mientras que dos docentes se refieren al enfoque inclusivo. También, retomaron la importancia por promover el respeto, la perspectiva de género y el conocimiento de la diversidad de los propios niños con miras en alcanzar su propio aprendizaje. En las respuestas de las maestras destaca el énfasis en poner en primer término a "las comunidades que más necesitan" con miras a un trato igualitario.

Con base en lo anterior, y retomando tanto el epígrafe del programa Nacional de Pueblos indígenas como diferentes frases del ejecutivo federal, se observa que han logrado trascender hasta llegar a las prácticas discursivas de las maestras por el énfasis que muestran por "los que menos tienen" o "más necesitan".

Por otro lado, considerando que "trabajar con la diversidad es normal; querer fomentarla es discutible; regular toda la variabilidad en los individuos es peligroso" (GIMENO, 1999, p.5), se observa la necesidad porque las docentes reciban procesos de formación especializados que les permita trascender una visión funcionalista del tratamiento de la diversidad en donde se reconocen e interactúan con el otro, pero en ocasiones aún se mantienen asimetrías sociales.

Sin embargo, no es realista pensar que la escuela sea capaz de asumir la diversidad en su totalidad, en primer lugar por cuestiones económicas debido a la imposibilidad de la escuela para atender las individualidades de cada estudiante (GIMENO, 1999, p.5). Otra razón es el tiempo, con grupos mayores a 25 estudiantes, incluso, en el nivel secundaria es común trabajar con grupos de 40 estudiantes, se orilla al docente a suprimir y priorizar necesidades para 'avazar' 
en el programa de estudios, para elegir temas de la evaluación, por un lado, y por otro para atender a su familia y necesidades personales, ya que a veces se olvida que el docente tiene una vida aparte de su rol en la escuela.

\section{Reflexiones finales}

Existen diferentes nociones sobre lo que es el enfoque intercultural. En este estudio se abordaron las perspectivas que Walsh (2011) y Dietz (2011) proponen para abordar el enfoque como objeto de estudio. Fue así que se contrastó dicho abordaje con las concepciones de las maestras entrevistadas donde se evidenció un énfasis por la perspectiva funcional (WALSH, 2011) de la interculturalidad y mayor presencia de las dimensiones inter-cultural e inter-actoral (DIETZ, 2011), pasando casi inadvertida la inter-lingüe.

Las docentes conocen el enfoque intercultural y coinciden en concebirlo como un proceso, pero por momentos lo confunden con el enfoque inclusivo. Asimismo, para trabajar didácticamente el enfoque intercultural fue interesante que dieran ejemplos donde muestran cómo lo transversalizan con contenidos de otras asignaturas y experiencias de la vida cotidiana. Este aspecto se relaciona con uno de los objetivos principales de las políticas educativas gubernamentales (CABRERO, 2000) expresadas en las últimas reformas, que consiste en promover la transversalización de la interculturalidad, la perspectiva de género y otros contenidos.

Asimismo, en las prácticas discursivas, todas las profesoras coincidieron en que la interculturalidad promueve la convivencia armónica y respetuosa. En este sentido y desde la observación participante (autoetnográfica), se registraron evidencias de que el alumnado tiene una apropiación natural del reconocimiento a la diferencia, pero al momento de confrontarse entre los diferentes, se denota el conflicto, que, en muchos de los casos, termina en algún tipo de violencia, ya sea verbal, física o psicológica. Por ello, como profesoras-investigadoras nos preguntamos ¿cómo aprender-enseñar- a convivir en el conflicto como parte natural de las relaciones interculturales, sin que culminen en actos violentos?

Por lo anterior, se hace evidente la necesidad del conflicto en las relaciones interculturales y tal vez por ello todas las maestras señalaron la importancia de promover una sana, armónica y necesaria convivencia porque entre los retos a los que se enfrentan esta el manejar los conflictos culturales que derivan de dichas diferencias. De acuerdo con la perspectiva crítica de la interculturalidad (Walsh, 2011) y la visión inter-cultural de Dietz (2011) el conflicto no sólo es necesario sino que es fundamental para reflexionar sobre las distintas relaciones sociales; el conflicto es un síntoma positivo de la democracia en el sentido de que "cuando todo es plano, cuando la palabra de uno es la palabra de todos, la democracia ha muerto" (DUMESNIL, 2006, p.4). Tomar en cuenta la voz de todos requiere de las opiniones de cada individuo aceptado como único y diferente, implica una disputa, una disidencia de opiniones, una crítica, la libertad de expresión, la descalificación, etc., es decir, es criticar la visión colonial y hegemónica de la sociedad.

Promover esos elementos en el aula, es una tarea compleja. Implica la interacción entre culturas aceptando, empatizando y respetando la diferencia, pero además logrando convivir entre ellas, constituye un reto necesario, porque como se observó, aún no se termina de comprender que la interculturalidad requiere una visión crítica (WALSH, 2011), que discuta nuestro status y el del otro, que entienda, construya y deconstruya la lógica cultural (DIETZ, 2011) de los diferentes grupos. Los docentes requieren mayor concienciación para discutir qué valores están promoviendo de acuerdo con el contexto del que forma parte él y sus estudiantes. Esto complejiza aún más la tarea de las políticas gubernamentales porque están alejadas de las dinámicas culturales y comunitarias, incluso, de las propias culturas magisteriales. En este sentido, sería viable que, retomando el enfoque de la NEM que propone mayor autonomía insti- 
-tucional, cada centro o zona escolar se comprometa en la conformación de políticas públicas (CABRERO, 2000), más que en reproducir o aplicar políticas gubernamentales.

Finalmente, en la denominada NEM, las docentes observan la intención de construir una relación más respetuosa con los docentes y con las comunidades. Reconocen parcialmente un viraje hacia las acciones afirmativas al intenta dar una atención mayor a los que menos tienen y más necesitan. En sus prácticas discursivas las docentes reconocen que la NEM enfatiza la formación cívica, los derechos humanos y el trato igualitario, sin embargo, como ya se explicó, esta política promueve el humanismo social, pero aún se encuentra en proceso de implementación. Es así que el tiempo se encargará de mostrar si no se trata de un enfoque más que se suma a enfoques como el de la educación bicultural, inclusivo o intercultural.

\section{Referencias bibliográficas}

BLANCO, Mercedes. “Autoetnografía: una forma narrativa de generación de conocimientos. Andamios Revista de Investigación Social, 9 (19), 49-74. Universidad Autónoma de la Ciudad de México. Distrito Federal, México: 2012.

BERTELY, María. Conociendo nuestras escuelas. Un acercamiento etnográfico a la cultura escolar,México: Paidós Mexicana, 2000.

CABRERO, Enrique. “Usos y costumbres en la hechura de las políticas públicas en México. Límites de las policy sciences en contextos cultural y políticamente diferentes". Gestión y Política Pública. IX (2): 2000

Cámara de diputados del H. Congreso de la Unión. Constitución politica de los Estados Unidos Mexicanos, $\quad 2020, \quad$ r e c u p r a d o d e http://www.diputados.gob.mx/LeyesBiblio/pdf_mov/Constitucion_Politica.pdf

Cámara de diputados del H. Congreso de la Unión. Constitución política de los Estados Unidos

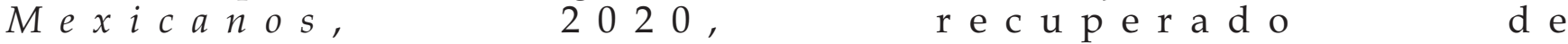
http://www.diputados.gob.mx/LeyesBiblio/pdf_mov/Constitucion_Politica.pdf

DIETZ, Gunther. Multiculturalism, Interculturality and Diversity in Education: an anthropological approach. Muenster \& Nueva York: Waxmann, 2009.

"Hacia una etnografía doblemente reflexive: una propuesta desde la antropología de la interculturalidad". AIBR. Revista de antropología Iberoamericana. 6 (1). 3-26: 2011.

DIETZ, Gunther; MATEOS CORTÉS, Laura S. Interculturalidad y educación intercultural en México. Un análisis de los discursos nacionales e internacionales en su impacto en los modelos educativos mexicanos. México: SEP-CGEIB, 2013.

DUMESNIL, Pierre. Conflictos y solidaridades. Revista Trasversales, 2, 2006.

ELLIS, C. "Autoethnography, Personal Narrative, Reflexivity. Researcher as Subject", en Denzin, N. y Lincoln, Y. (eds.), Collecting and Interpreting Qualitative Materials, Thousand Oaks, California:Sage: 2003. 
GIMENO, Sacristán José. La construcción del discurso acerca de la diversidad y sus prácticas. Aula de innovación educativa, 81, 82,1-19: 1999.

MATO, D. "Interculturalidad, producción de conocimientos y prácticas socioeducativas". Alceu 6 (11) 120-138. Pontificia Universidad Católica de rio de Janeiro: 2005

JIMENEZ, Yolanda, "Los "enunciados" de la escuela intercultural en el ámbito de los pueblos indígenas de México", Desacatos, 35: 149-162: 2011.

PÉREZ, Ruíz Maya Lorena. ¿De qué hablamos cuando nos referimos a lo intercultural? Reflexiones sobre su origen, contenidos, aportaciones y limitaciones. En Estados Plurales. Los retos de la diversidad y la diferencia. Laura R. Valladares de la Cruz, Et. Al. (Coords.). México: PorrúaJuan Pablos Ed, 2009.

RESTREPO, Eduardo. Relevancia conceptual de Michel Foucault para los estudios contemporáneos de la etnicidad. En: E. Restrepo: Teorías contemporáneas de la etnicidad: Stuart Hall y Michel Foucault, pp. 73-102, Popayán: Editorial Universidad del Cauca, 2004.

RICHARDSON, L. (2003), “Writing. A Method of Inquiry”, en Denzin, N. y Lincoln, Y. (eds.), Collecting and Interpreting Qualitative Materials, Thousand Oaks, California: Sage.

ROCCO, Leonardo; OLIARI, Natalia. "La encuesta mediante internet como alternativa metodológica". VII Jornadas de Sociología. Facultad de Ciencias Sociales, Universidad de Buenos Aires, Buenos Aires: 2007

RODRÍGUEZ Gómez, G., Gil Flores, J. y García Jiménez, E. Metodología de la Investigación Cualitativa. España: Ediciones Aljibe, 1999.

SEP. Consejo Técnico Escolar. Fase intensiva. Educación preescolar, primaria y secundaria. Ciclo escolar 2019-2020. Guía de trabajo. México: SEP, 2019.

Es educación la parte más dinámica y eje de la Cuarta Transformación: Moctezuma Barragán. Boletín SEP No.112,29 d e julio de 2019 , recuperado d e https://www.gob.mx/cms/uploads/attachment/file/481220/Boleti_n SEP_no. 112_Es_educacio_n_la_parte_ma_s_dina_mica_y_eje_de_la_Cuarta_Transformacio_n_Moctezuma_Barra ga n.pdf

. Hacia una Nueva Escuela Mexicana. Taller de capacitación. Educación básica ciclo escolar 20192020. México: SEP, 2 de agosto, 2019.

. Plan de estudios 2011. Educación básica, México:SEP, 2011.

SCHMELKES, S. La educación intercultural: un campo en proceso de consolidación. Revista Mexicana de Investigación Educativa, 20(9), 9-13, 2004 (enero-marzo).

TAYLOR. S. J. y Bogdan, R. Introducción a los métodos cualitativos de investigación. Paidós, Buenos Aires: 1986.

VIDAL, Díaz de Rada. “Ventajas e inconvenientes de la encuesta por Intenet. Papers. Revista de Sociología 97 (1). 193-223: 2011.

WALSH, Catherine, Etnoeducación e interculturalidad en perspectiva decolonial. Lima, Perú: CEDET, 2011.

EntreRios - Revista do PPGANT -UFPI -Teresina • Vol. 3, n. 1 (2020) 